\title{
ANALYSIS OF MINING ORE CONCENTRATES WITH A LOW COST PORTABLE LIBS SYSTEM
}

\author{
Omar Ormachea, Alex Villazón e Iván Terceros
}

\begin{abstract}
Identifying minerals in ore concentrates require costly techniques and preparation of samples, thus limiting their instant analysis. We present the development of a low-cost portable LIBS (Laser Induced Breakdown Spectroscopy) system, to identify atomic elements in ore concentrates in-situ and in real-time. The system consists of a YAG:Nd ${ }^{+++}$ pulsed laser, an optical diffraction spectrometer, and a measurement gun consisting of a laser head and an optical system for collecting light from the sample. We developed customized software for data acquisition, processing and analysis that stores and uses the principal spectral lines of referential atomic elements $(\mathrm{Cu}, \mathrm{Pb}, \mathrm{Ag}, \mathrm{Au}, \mathrm{Li}, \mathrm{Zn}) . \mathrm{We}$ experimentally obtained spectra of selected samples using our LIBS system, and successfully matched them with the referential spectral lines. Finally, we tested our system with real samples of ore concentrates from a mining company, where the presence of $\mathrm{Zn}$ was successfully detected through its characteristic spectrum.
\end{abstract}

Keywords: LIBS, Atomic Emission Spectroscopy,Lasers, Spectrometers.

DOI: $10.23881 /$ idupbo.018.1-6i 